\title{
Extra-genital lichen sclerosus in a patient with anti-SS-A antibody
}

\section{Tatsuhiko Mori, Toshiyuki Yamamoto}

Department of Dermatology, Fukushima Medical University, Fukushima 960-1295, Japan

Corresponding author: Prof. Toshiyuki Yamamoto, E-mail: toyamade@fmu.ac.jp

Sir,

Lichen sclerosus (LS) is a rare chronic inflammatory skin disease generally affecting oral and genital areas, and rarely occurs on the neck, shoulders, upper trunk, axillae, and thighs. We describe herein a case of extragenital LS involving a large area on the back, in which serum anti-SS-A antibody was detected.

A 25-year-old female was referred to our department, complaining of symptomless, whitish macules on the nape and upper back that appeared six months previously. On physical examination, macular lesions were located on the nape, upper back, and lower back (Fig. la). A number of whitish spots were observed within the large round, slightly shiny macules on the nape extending to the upper back (Fig. 1b). On the lower back, a few erythematous macules also had pigmented spots (Fig. 1c). There was no skin sclerosis. A biopsied specimen taken from the upper back showed that the epithelium was reduced in thickness, and moderate liquefaction was found in the basal layers. The most remarkable feature was homogenized and hyalinized degeneration of collagen fibers with marked edema just below the epidermis (Fig. 2). Laboratory data on blood chemistry including liver and renal function were within the normal range. Antinuclear antibodies (ANA) (1:80, homogeneous and speckled) and anti-SS-A antibody $(83.0 \mathrm{U} / \mathrm{ml})$ were detected in the serum, whereas rheumatoid factor, and serum antibodies against SS-B, thyroid and microsome were all within normal ranges. A diagnosis of LS was made. There were no other similar appearing lesions on her body including genitalia. We applied topical corticosteroid (betamethasone butyrate propionate) ointment, and the lesions gradually improved after two months. In the present case, atrophic macules were observed relatively diffusely on the back without vulvar involvement. The differential diagnosis of LS includes generalized morphea and vitiligo-like depigmentation associated with systemic sclerosis, which were denied by histological examination LS is sometimes associated with other autoimmune diseases, among which autoimmune thyroid disease is the most frequent [1-3]. In our patient, serological examination revealed positive ANA (1:80) and antiSS-A antibody, whereas anti-SS-B antibody was within normal ranges. Additionally, she denied sicca syndrome. Detailed tear and saliva examination denied Sjögren's syndrome $(\mathrm{SjS})$. To date, anti-SS-A antibody has been detected in only one co-existence case of LS and systemic sclerosis [4]. A previous study examined the association of LS and autoimmune disease, and found no association with $\mathrm{SjS}$ in 190 female patients with LS [1]. Also, other studies examined autoantibodies in a number of patients with LS; however, anti-SS-A antibody was not detected [2,3]. In a recent report

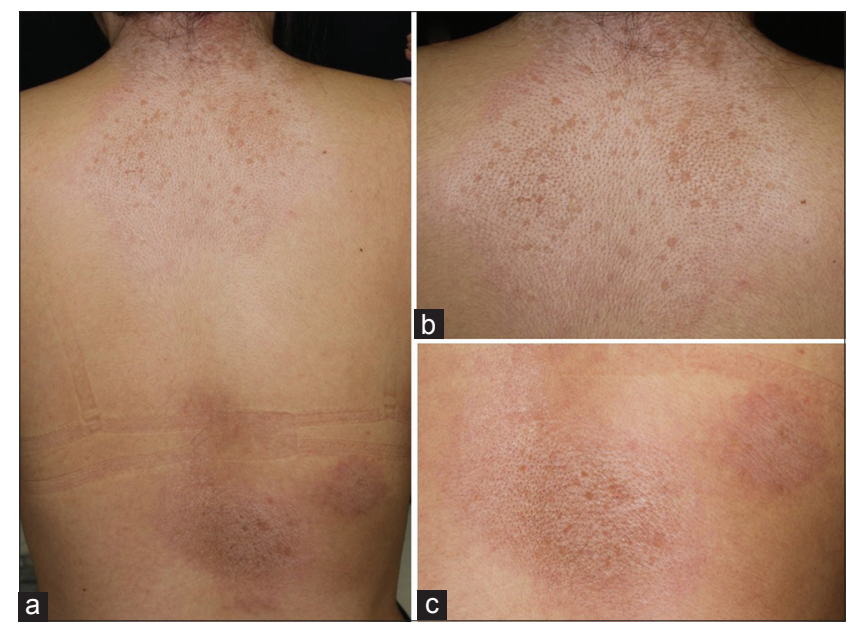

Figure 1:Macular atrophic lesions on the nape, upper back, and lower back (a-c).

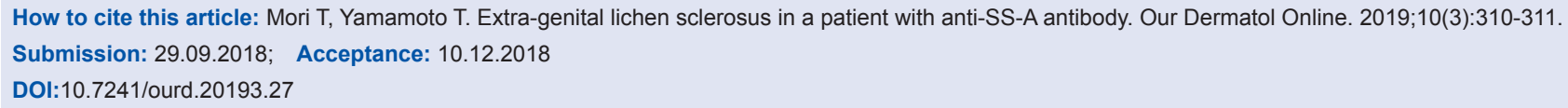




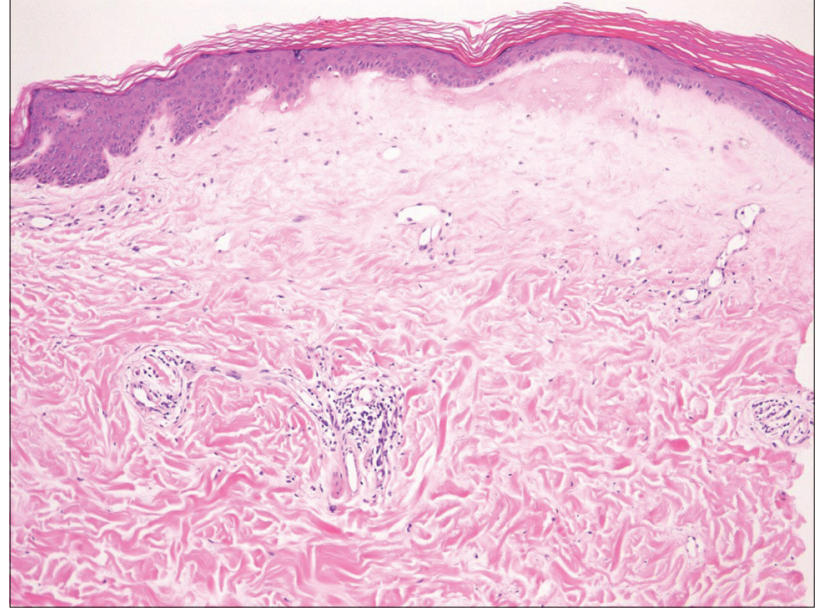

Figure 2:Histological features showing epidermal atrophy and homogeneous degeneration beneath the epidermis.

from Lebanon, nine out of $60 \mathrm{LS}$ patients (15\%) had at least one associated autoimmune disease, among which five cases of localized scleroderma, three cases of autoimmune thyroid disease, and one case of SLE were observed [5], but none had $\mathrm{SjS}$. In conclusion, to our knowledge, there have been no reports on associated cases of $\mathrm{LS}$ and $\mathrm{Sj}$; however, our patient is under follow-up to examine whether $\mathrm{SjS}$ will develop in the future.

\section{Consent}

The examination of the patient was conducted according to the Declaration of Helsinki principles.

\section{REFERENCES}

1. Cooper SM, Ali I, Baldo M, Wojnarowska F. The association of lichen sclerosus and erosive lichen planus of the vulva with autoimmune disease: a case-control study. Arch Dermatol. 2008;144:1432-5.

2. Kreuter A, Kryvosheyeva Y, Terras S, Moritz R, Möllenhoff K, Altmeyer P, et al. Association of autoimmune diseases with lichen sclerosus in 532 male and female patients. Acta Derm Venereol. 2013;93:238-41.

3. Meyrick-Thomas RH, Ridley CM, McGibbon DH, Black MM. Lichen sclerosus et atrophicus and autoimmunity: a study of 350 women. Br J Dermatol. 1988;118:41-6.

4. Branişteanu DE, Branişteanu DC, Stoleriu G, Ferariu D, Voicu CM, Stoica LE, et al. Histopathological and clinical traps in lichen sclerosus: a case report. Rom J Morphol Embryol. 2016;57:817-23.

5. Knio Z, Kurban M, Abbas O. Lichen sclerosis: clinicopathological study of 60 cases from Lebanon. Int J Dermatol. 2016;55:1076-81.

Copyright by Tatsuhiko Mori, et al. This is an open-access article distributed under the terms of the Creative Commons Attribution License, which permits unrestricted use, distribution, and reproduction in any medium, provided the original author and source are credited.

Source of Support: Nil, Conflict of Interest: None declared. 